\title{
Effect of Serum Trace Elements, Macro-minerals and Antioxidants in Acne Vulgaris Patients: A Case-Control Study
}

\author{
Salma Ahmed ${ }^{1 \Psi}$, Rubaiya $\mathrm{Ali}^{2 \Psi}$, Md. Reazul Islam ${ }^{3}$, Md. Anamul Hoque ${ }^{1}$, \\ Abul Hasnat ${ }^{3}$ and Zabun Nahar ${ }^{1}$
}

\author{
${ }^{1}$ Department of Pharmacy, Northern University Bangladesh, Dhaka-1205, Bangladesh \\ ${ }^{2}$ Department of Dermatology and Venereology, Ad-Din Women's Medical College, Dhaka- 1217, Bangladesh \\ ${ }^{3}$ Department of Clinical Pharmacy and Pharmacology, Faculty of Pharmacy, University of Dhaka, Dhaka-1000, \\ Bangladesh
}

(Received: October 05, 2016; Accepted: December 08, 2016; Published (web): December 27, 2016)

\begin{abstract}
Acne vulgaris is a chronic skin disease with multifaceted cause. The exact etiology and pathogenesis of acne are yet to be established completely and various causative factors are considered as pathogenic mechanisms in the development of this disorder. We designed a study to determine the extent of serum trace elements, macrominerals and antioxidants in patients with acne, and thereby, to find the pathophysiological correlations, if any. Serum trace elements and macro-minerals were determined by flame atomic absorption spectroscopy. RP-HPLC was used to quantify antioxidants. Significantly $(\mathrm{p}<0.05)$ decreased level of zinc $(1.90 \pm 0.06 \mathrm{vs} .2 .17 \pm 0.09 \mathrm{mg} / \mathrm{L})$, calcium ( $115.64 \pm 4.84$ vs. $197.05 \pm 7.11 \mathrm{mg} / \mathrm{L})$ and vitamin A ( $0.2 \pm 0.06$ vs. $0.86 \pm 0.26 \mu \mathrm{mol} / \mathrm{L})$ was found in patient when compared with the corresponding controls. This investigation suggests a commendable association between the pathogenesis of acne vulgaris with the reduced level of zinc, calcium and vitamin A which could well be used as a diagnostic tool for acne vulgaris.
\end{abstract}

Key words: Trace elements, antioxidants, macro-minerals, acne vulgaris

\section{INTRODUCTION}

Acne vulgaris is one of the most commonly occurring skin diseases, which affects almost 80 percent of people at some time between the ages of 11 to 30 years. ${ }^{1}$ It can persist for several years and results in disfigurement and permanent scarring. It also can have serious unwanted effects on mental development, like emotional problems, withdrawal symptoms, and depression. ${ }^{2}$ Generally, acne vulgaris affects those areas of the body which have hormonally sensitive sebaceous glands, predominantly the face, neck, chest, upper arms and upper back. The amplitude of acne vulgaris has increased significantly in many countries of the world in recent decades. This increase has thought to be

Correspondence to: Zabun Nahar

Email: zabun_nahar@yahoo.com

${ }^{\Psi}$ These authors have equal contribution

Dhaka Univ. J. Pharm. Sci. 15(2): 215-220, 2016 (December) correlated with malnutrition, lifestyle change and environmental factors. ${ }^{2}$ However, in addition to occupational studies of skin disease, some investigations have found a relationship between family histories with acne vulgaris, especially in adults. ${ }^{3}$ Such relationships between genetic factors and acne vulgaris are well reported; though less is known about some other parameters such as environment and diet. ${ }^{4}$ Essential trace elements and macro-minerals are vital to nutrition and sound health. ${ }^{5}$ The importance of minerals such as calcium, sodium and chloride in human nutrition has been well established. ${ }^{6}$ Trace elements or micro-minerals are essential to various biochemical processes in human body which are also involved in immunological functions. ${ }^{7}$ Trace elements play versatile roles in our body ranging from immunity development to providing antioxidant defense. ${ }^{8,9}$ They perform their 
function by interacting with biomolecules in human body. It has been seen that elemental content is often related to several skin diseases and trace elements activate a great number of enzymes that are involved in the disease evaluation and its treatment. ${ }^{10}$ Imbalances of different trace elements and macrominerals may adversely affect biological functions and are associated with skin diseases such as acne vulgaris. ${ }^{11}$ Oxidative stress may occur due to the deficiency of trace elements like copper, manganese, zinc and selenium ${ }^{12}$, which is known to be one of the major causative agents in acne vulgaris patients. ${ }^{13}$ There are some studies regarding the correlation between zinc deficiencies and acne. These studies are few in number but have claimed that patients suffering from acne have low serum zinc levels than normal individuals. ${ }^{14}$ Although we found few studies on the serum levels of copper, manganese and other trace elements in acne patients worldwide, but no such study has been done in Bangladesh. It has become clear that nutritional factors like vitamins are involved in acne development. ${ }^{15}$ In addition, synthetic antioxidants may have several unwanted effects on our body; so much attention has been put toward various natural antioxidants. ${ }^{15}$ Antioxidants derived from dietary sources and they are also known as non-enzymatic antioxidants including fat-soluble vitamins like vitamin $\mathrm{A}$ (retinol) and vitamin $\mathrm{E}$ (tocopherol) ${ }^{16}$ Vitamin $\mathrm{A}$ and $\mathrm{E}$ are essential for our health and their deficiency can cause serious diseases. Vitamin A deficiency is thought to be associated with suppressed mucus secretion results in keratinized and scaly skin. ${ }^{17}$ Common signs of vitamin A deficiency are rough and dry skin, which often first appears as rough, raised bumps on the back of the arms. ${ }^{18}$ On the other hands, patients with acne were shown to improve their acne condition after administration of vitamin $\mathrm{A}$ and $\mathrm{E} .{ }^{14}$

So, the aim of our study to demonstrate and compare the serum level of different trace (zinc, copper and manganese) elements, macro-minerals (calcium and magnesium) and vitamins (vitamin A and E) of acne patients with that of the control group to find out whether there is any clinically significant relationship exist between them.

\section{MATERIALS AND METHODS}

Sixty five acne vulgaris patients (49 females and 16 males with a mean age of $29.3 \pm 2$ years) were recruited randomly from outpatient department of Ad-Din Women's Medical College by a dermatologist and 65 sex and age-matched healthy volunteers (48 females and 17 males with a mean age of $29.5 \pm 2$ years) were recruited as control subjects. The purpose of the study was thoroughly explained to all the subjects and written consent form was filled up by each of them. Different clinical examinations of the study subjects were performed to identify the presence of other diseases, which might change the study parameters. Routine physical checkup including their organ activity, nutritional condition, weight, blood pressure and chest X-ray was performed for all study subjects. Blood urea nitrogen, hematocrit, glucose, liver enzyme and creatinine tests were also conducted to find out their pathological conditions for all subjects. These subjects were free from diabetes, kidney failure, or other disease and they were not treated with drugs (antihypertensives, diuretics, mineral supplements, etc.), which can interfere with the concentration of the elements. Ethical approval was obtained from the Medical College authority.

Blood sample collection and serum separation. Venous blood $(5 \mathrm{ml})$ was drawn from each subject using a syringe fitted with a stainless steel needle. Then the collected blood was allowed to clot for at least $1 \mathrm{~h}$ at room temperature. Centrifugation was performed at $3000 \mathrm{rpm}$ for $15 \mathrm{~min}$ to separate the serum. The serum was stored at $-80^{\circ} \mathrm{C}$ until quantitative analysis. Precautions were taken to eliminate all metal contamination during blood collection, processing and storage according to criteria set by National Committee for Clinical Laboratory Standards. ${ }^{19}$

Chemicals and reagents. Analytical and HPLC grade chemicals and solvents were used as appropriate.

Determination of serum trace elements and macro-minerals level. Measurement of serum trace elements and macro-minerals level was performed by 
flame atomic absorption spectrometry (FAAS, Spectra AA 220). Samples were diluted with deionized water and dilution factor was 10 . Calibration curve was prepared from the different concentrations $(0.5,1.0,5.0,10.0$ and $12.0 \mathrm{mg} / \mathrm{L})$ of standard minerals. Absorbance was measured at $213.8,327.5,279.9,421.5$, and $286.2 \mathrm{~nm}$ for zinc, copper, manganese, calcium, and magnesium respectively. Quality and assay accuracy were maintained by applying standard solutions for every ten samples. Software named Spectra AA was used to determine the concentration of trace and macrominerals.

Measurement of vitamin A and E. Vitamin A (retinol) and vitamin $\mathrm{E}$ ( $\alpha$-tocopherol) were measured by liquid-liquid extraction method in RP-HPLC using N-hexane which was evaporated to dryness using a Sample Concentrator at $40^{\circ} \mathrm{C}$ under a nitrogen steam. Then, the dried extract was reconstituted using mobile phase. From the reconstituted sample, $20 \mu \mathrm{L}$ was carefully injected into a $\mathrm{C}_{18}$ (Nucleosile) column with a mobile phase of $90 \%$ methanol and $10 \%$ water at a flow rate of $1 \mathrm{ml} / \mathrm{min}$.

Statistical analysis. Data are presented here as mean \pm standard error mean (SEM). To find out the correlation among various parameters, Pearson's correlation analysis was performed. Independent sample t- test and cross table variables were used to compare all the parameter of acne patients and controls. Statistical software package SPSS (version 22.0) was used to perform all those tests.

\section{RESULTS AND DISCUSSION}

Serum trace elements and macro-minerals

level. Serum levels of trace elements and macrominerals are shown in table 1 and the average values of serum zinc, copper, manganese, calcium and magnesium were $1.90 \pm 0.06,6.89 \pm 0.66,4.64 \pm 0.68$, $115.64 \pm 4.84$ and $31.24 \pm 2.04 \mathrm{mg} / \mathrm{l}$ respectively for patient group and $2.17 \pm 0.09,6.48 \pm 0.21,4.45 \pm 0.5$, $197.05 \pm 7.11$ and $28.31 \pm 0.87 \mathrm{mg} / \mathrm{l}$ for the healthy control group. Statistically significant $(p<0.05)$ lower level of serum zinc and calcium was observed in acne patients when compared with the control group.
Serum antioxidant vitamin levels. The serum levels of vitamin A and $\mathrm{E}$ were $0.2 \pm 0.06$ and $2.96 \pm 0.48 \mu \mathrm{mol} / 1$ for the patients and $0.86 \pm 0.26$ and $4.06 \pm 0.78 \mu \mathrm{mol} / 1$ for the control group, respectively, and we found a significantly lower $(\mathrm{p}<0.05)$ level of vitamin $\mathrm{A}$ in the patient group (Table 2).

Correlation analysis among different trace elements and macro-minerals. The inter-element correlations of the tested elements between patients and controls were analyzed by Pearson's test which showed either positive (direct) or negative (inverse) correlations for some elements. Table 3 shows the correlations among various parameters with their coefficient. In the patient group, we found a significantly positive correlation between $\mathrm{Zn}$ and $\mathrm{Mg}$ $(\mathrm{r}=0.287, \mathrm{p}=0.044) ; \mathrm{Ca}$ and $\mathrm{Mg}(\mathrm{r}=0.571, \mathrm{p}=$ 0.001). In the control group, we found positive relationship between $\mathrm{Cu}$ and $\mathrm{Mn}(\mathrm{r}=0.413, \mathrm{p}=$ $0.003)$; $\mathrm{Ca}$ and $\mathrm{Mg}(\mathrm{r}=0.552, \mathrm{p}=0.002)$. Inverse correlations between elements were not significant.

Trace elements, macro-minerals and vitamins are essential elements that play vital roles in the biochemical processes of our body. ${ }^{20}$ The relationship between certain minerals and acne vulgaris is a concern of ongoing investigation. Till date, only a few studies are available those highlight the role of minerals in the disease progression of acne. Minerals act as essential co-factors for all enzymatic reactions in human body. The normal level of trace elements in our blood is very important for healthy skin. ${ }^{20}$ They play a crucial role in immunity system and alteration of normal homeostasis of these elements in our body may adversely affect different biological processes leading to unwanted complications. ${ }^{21}$ Since ancient ages, human are using macro-minerals for their therapeutic effects on skin. ${ }^{13} \mathrm{Zn}$ is a trace element that is considered as a vital mineral for skin health. It is important for the activation of local skin hormone level, inflammation control and skin cell regeneration etc. $^{22}$ Moreover, $\mathrm{Zn}$ binds with several proteins in human body and the biological activities of these $\mathrm{Zn}$ bound proteins depend on the appropriate concentration of $\mathrm{Zn}$ in our body. ${ }^{23}$ The deficiency of 
Table 1. Serum levels of trace elements and macro-minerals in patients and control group.

\begin{tabular}{lccc}
\hline Parameter & Patient group $(\mathrm{mg} / \mathrm{l})$ & Control group $(\mathrm{mg} / \mathrm{l})$ & $\mathrm{p}$ value \\
\hline Zinc & $1.90 \pm 0.06$ & $2.17 \pm 0.09$ & $0.01^{*}$ \\
Copper & $6.89 \pm 0.66$ & $6.48 \pm 0.21$ & 0.557 \\
Manganese & $4.64 \pm 0.68$ & $4.45 \pm 0.5$ & 0.823 \\
Calcium & $115.64 \pm 4.84$ & $197.05 \pm 7.11$ & $0.000^{*}$ \\
Magnesium & $31.24 \pm 2.04$ & $28.31 \pm 0.87$ & 0.191 \\
\hline
\end{tabular}

$* \mathrm{p}<0.05$, is significant

All values are expressed in mean \pm SEM

Table 2. Serum levels of antioxidant vitamins in patients and control group.

\begin{tabular}{lccc}
\hline Parameter & Patient group $(\mu \mathrm{mol} / \mathrm{l})$ & Control group $(\mu \mathrm{mol} / \mathrm{l})$ & $\mathrm{p}$ value \\
\hline Vitamin A & $0.2 \pm 0.06$ & $0.86 \pm 0.26$ & $0.02 *$ \\
Vitamin E & $2.96 \pm 0.48$ & $4.06 \pm 0.78$ & 0.234 \\
\hline
\end{tabular}

$* \mathrm{p}<0.05$, is significant

All values are expressed in mean \pm SEM

Table 3. Study of inter-element correlations.

\begin{tabular}{lcccc}
\hline \multirow{2}{*}{$\begin{array}{c}\text { Correlation } \\
\text { parameter }\end{array}$} & \multicolumn{2}{c}{ Patient group } & \multicolumn{2}{c}{ Control group } \\
\cline { 2 - 5 } & $\mathrm{r}$ & $\mathrm{p}$ & $\mathrm{r}$ & $\mathrm{p}$ \\
\hline $\mathrm{Zn}$ and $\mathrm{Cu}$ & 0.074 & 0.607 & -.039 & 0.786 \\
$\mathrm{Zn}$ and $\mathrm{Mn}$ & 0.012 & 0.934 & 0.045 & 0.754 \\
$\mathrm{Zn}$ and $\mathrm{Ca}$ & -0.004 & 0.987 & 0.028 & 0.848 \\
$\mathrm{Zn}$ and $\mathrm{Mg}$ & 0.287 & $0.044^{*}$ & 0.139 & 0.336 \\
$\mathrm{Cu}$ and $\mathrm{Mn}$ & 0.031 & 0.830 & 0.413 & $0.003^{* *}$ \\
$\mathrm{Cu}$ and $\mathrm{Ca}$ & -0.133 & 0.356 & 0.013 & 0.929 \\
$\mathrm{Cu}$ and $\mathrm{Mg}$ & -0.230 & 0.108 & 0.109 & 0.450 \\
$\mathrm{Mn}$ and $\mathrm{Ca}$ & -0.015 & 0.917 & 0.293 & $0.039^{*}$ \\
$\mathrm{Mn}$ and $\mathrm{Mg}$ & -0.070 & 0.627 & 0.223 & 0.120 \\
$\mathrm{Ca}$ and $\mathrm{Mg}$ & 0.571 & $0.001^{* *}$ & 0.552 & $0.002^{* *}$ \\
\hline
\end{tabular}

Values with negative sign indicate an inverse correlation

$r$ correlation co-efficient, $p$ significance

* Correlation is significant at 0.05 level (two-tailed)

** Correlation is significant at 0.01 level (two-tailed)

$\mathrm{Zn}$ can cause dermatitis and decreased immune function and is commonly found in patients with growth retardation and skin lesions. ${ }^{23,24}$ Our study also corroborates these findings as significant decrease in the serum zinc concentration of acne vulgaris patients compared to the control subjects $(p=0.01){ }^{23}$ In our study, a change in serum concentration of $\mathrm{Cu}$ between patient and control group was not significant like some previous studies. $^{25}$ However, we did not find any significant change in the serum level of Mn but one study does not support this finding. ${ }^{26}$
Macro-minerals such as sodium $(\mathrm{Na})$, potassium $(\mathrm{K})$, calcium $(\mathrm{Ca})$ and magnesium $(\mathrm{Mg})$ etc. have vital role in maintaining good health. In order to enjoy a healthy life, our diet should contain these macro-minerals in adequate quantities. ${ }^{27} \mathrm{Ca}$ plays a significant role in different enzymes activation and also in the maintenance and formation of bone. Moreover, $\mathrm{Ca}$ is involved in neuromuscular excitability. ${ }^{27} \mathrm{Ca}$ deficiency, due to poor nutritional status is a risk factor for various chronic diseases. Moreover, Ca deficiency can lead to osteoporosis, osteoarthritis, hypertension, various cancers, and many other cardiovascular diseases. ${ }^{28} \mathrm{Mg}$ is an 
important macro-mineral, which plays some vital role like oxidative phosphorylation, energy production, and glycolysis. It is required for the synthesis of glutathione, DNA, RNA and for the structural development of bone. Magnesium additionally assumes a part in the active transport of calcium and potassium ions across cell membranes that are important for normal heart rhythm, nerve impulse conduction and muscle contraction. ${ }^{29}$ To our knowledge, there is no study available regarding the determination of the status of $\mathrm{Ca}$ and $\mathrm{Mg}$ in patients with acne vulgaris. Our result found significantly lower level of calcium in acne patients when compared to control subjects $(\mathrm{p}<0.001)$ which is supported by a previous study where decreased concentration of calcium in endoplasmic reticulum was found to be the cause of darier keratinocytes, one kind of skin disease. ${ }^{30}$

Though potentially harmful, reactive oxygen species (ROS) are essential for biological functions. ${ }^{31}$ Lipid peroxidation, which is harmful to health, occurs through a free radical chain reaction mechanism where oxygen acts as a vital element. ${ }^{32}$ There should be balance between production and elimination of ROS which is crucial for proper maintenance of a healthy biological system. ${ }^{31}$ Antioxidant vitamins scavenge and inhibit the development of free radicals or oppose their actions. ${ }^{33}$ Moreover, antioxidants also prevent lipid peroxidation by free radical inactivation. ${ }^{34}$ Our study showed a significantly lower level of vitamin A $(p=0.02)$ in acne patients in comparison with controls, but the difference between vitamin E was not significant. According to an earlier study, retinoids (a chemical form of vitamin A) was used to treat acne vulgaris which suggests that vitamin A deficiency can be a causative factor of this disease which we found in our study as well. ${ }^{35}$ Therefore, our study suggests that significant reduction of these elements in serum levels may trigger the pathogenesis of acne vulgaris.

\section{CONCLUSION}

In this study, we explored that acne vulgaris patients have a decreased serum concentration of trace elements, macro-minerals, vitamin $\mathrm{A}$ and vitamin $\mathrm{E}$ when compared to the healthy individuals. The study strongly suggests that reduced level of serum trace elements, macro-minerals, and antioxidants may contribute to the pathogenesis of acne vulgaris.

\section{REFERENCES}

1. James, W.D. 2005. Clinical practice; Acne. N. Engl. J. Med. 352, 1463-1472.

2. Mogaddam, R.M., Ardabili, S.N., Maleki, N. and Maedeh, S. 2014. Correlation between the severity and type of acne lesions with serum zinc levels in patients with acne vulgaris. Biomed. Res. Int. 474, 1-6.

3. Kurt, E., Metintas, S., Basyigit, I., Bulut, I., Coskun, E., Dabak, S., Deveci, F., Fidan, F., Kaynar, H., Kunt, U.E., Onbasi, K., Ozkurt, S., Pasaoglu, K.G., Sahan, S., Sahin, U., Oguzulgen, K., Yildiz, F., Mungan, D., Yorgancioglu, A., Gemicioglu, B. and FuatKalyoncu, A. 2009. Prevalence and risk factors of allergies in Turkey (PARFAIT): results of a multicentercross-sectional study in adults. Eur. Respir. J. 33,724-733.

4. Harris, J.M., Cullinan, P., Williams, H.C., Mills, P., Moffat, S., White, C., Yaylor, A.J.N. 2001. Environmental associations with eczema in early life. Br. J. Dermatol. 144, 795-802.

5. Toyran, M., Kaymak, M., Vezir, E., Harmanc1, K., Kaya, A., Ginis, T., Kose, G. and Kocabas, C.N. 2012. Trace element levels in children with atopic dermatitis. J. Investig. Allergol. Clin. Immunol. 22, 341-344.

6. Williams, M., H. 2005. Dietary supplements and sports performance: minerals. J. Int. Soc. Sports Nutr. 11, 43-49.

7. Kulkarni, N., Kalele, K., Kulkarni, M. and Kathariya, R. 2014. Trace elements in oral health and disease: an updated review. J. Dent. Res. Rev. 1,100-104.

8. Zemel, B.S., Kawchak, D.A., Fung, E.B., Ohene-Frempong, K. and Stallings, V.A. 2002. Effect of zinc supplementation on growth and body composition in children with sickle cell disease. Am. J. Clin. Nutr. 75, 300-307.

9. Hallberg, L., Sandestrom, B., Ralph, A. and Arthur, J. 2000. Iron, zinc and other trace elements. In: Garrow JS, James WPT, Ralph A (eds) Human nutrition and dietetics, 10th edn. Harcourt Publishers Ltd. Churchill Livingstone, pp. 177-210.

10. Werner-Lindle, Y., Pallon, J. and Forslind, B. 1998. Physiologically Important Trace Elements of Paralesional Psoriatic Skin. Scanning Microscopy 12, 599-608.

11. Saleh, O.B., Anbar, H.N.Z. and Majid, Y.A. 2011. Serum Trace Elements (Zinc, Copper and Magnesium) Status in Iraqi Patients with Acne Vulgaris. Iraqi J. Pharm. Sci. 20, 44-49.

12. Mohamad, N.S. 2013. Trace elements homeostatic imbalance in mild and severe psoriasis: a new insight in biomarker diagnostic value for psoriasis. Our Dermatol. Online 4, 449452.

13. Burris, J., Rietkerk, W., Woolf, K. 2014. Relationships of self-reported dietary factors and perceived acne severity in a cohort of New York young adults. J. Acad. Nutr. Diet 114, 384-392.

14. Katzman, M. and Logan, A.C. 2007. Acne vulgaris: nutritional factors may be influencing psychological sequelae. Med. Hypotheses 69, 1080-1084.

15. Halliwell, B. 2012. Free radicals and antioxidants: updating a personal View. Nutr. Rev. 70, 257-265. 
16. Islam, M.R., Ahmed, M.U., Islam, M.S., Sayeed, M.S., Sadia, F., Chowdhury, Z.S., Nahar, Z. and Hasnat, A. 2014. Comparative Analysis of Serum Malondialdehyde, Antioxidant Vitamins and Immunoglobulin Levels in Patients Suffering from Generalized Anxiety Disorder. Drug Res. 64, 406-411.

17. Bates, C.J. 1995. Vitamin A. Lancet 345, 31-35.

18. Kotori, M.G. 2015. Low-dose Vitamin "A" Tablets-treatment of Acne Vulgaris. Med. Arch. 69, 28-30.

19. NCCLS. 1997. Control of pre-analytical variation in trace element determination. Nat. Committ. Clin. Lab Stand. Appr. Guid. 17, 1-30.

20. Wintergerst, E.S., Maggini, S. and Hornig, D.H. 2007. Contribution of selected vitamins and trace elements to immune function. Ann. Nutr. Metab. 51, 301-323.

21. Islam, M.R., Ahmed, M.U., Mitu, S.A., Islam, M.S., Rahman, G.K., Qusar, M.M. and Hasnat, A. 2013. Comparative analysis of serum zinc, copper, manganese, iron, calcium, and magnesium level and complexity of interelement relations in generalized anxiety disorder patients. Biol. Trace Elem. Res.154, 21-27.

22. Fukada, T., Yamasaki, S., Nishida, K., Murakami, M. and Hirano, I. 2011. Zinc homeostasis and signaling in health and diseases: zinc signaling. J. Biol. Inorg. Chem. 16, 1123-1134.

23. Maret, W. and Sandstead, H.H. 2006. Zinc requirements and the risks and benefits of zinc supplementation. J. Trace Elem. Med. Biol. 20, 3-18.

24. Afridi, H.I., Kazi, T.G., Jamali, M.K., Kazi, G.H. and Shar, G.Q. 2006. The status of trace and toxic elements in biological samples (scalp hair) of skin-disease patients and normal subjects. Turk. J. Med. Sci. 36, 223-230.

25. El-Saaiee, L., Abdel-Aal, H., El-Mahdy, H. and Abdel-Aal, A.M. 1983. Serum copper, iron and zinc in cases of acne vulgaris. J. Med. 14, 125-136.
26. Sullivan, M. 1940. Manganese hydroxide in the treatment of acne vulgaris, pustular acne, furunculosis, sycosis vulgaris and psoriasis. JAMA 114, 246-248.

27. Soetan, K.O., Olaiya, C.O. and Oyewole, O.E. 2010. The importance of mineral elements for humans, domestic animals and plants: a review. Afr. J. Food Sci. 200-222.

28. Peterlik, M., Ka'llay, E. and Cross, H.S. 2013. Calcium nutrition and extracellular calcium sensing: relevance for the pathogenesis of osteoporosis, cancer and cardiovascular diseases. Nutrients 5, 302-327.

29. Rude, R.K., Ross, A.C., Caballero, B., Cousins, R.J., Tucker, K.L. and Ziegler, T.R. 2012. Modern Nutrition in Health and Disease. 11th ed. Baltimore, Mass: Lippincott Williams \& Wilkins, pp. 159-175.

30. Savignac, M., Edir, A., Simon, M. and Hovnanian, A. 2011. Darier disease: a disease model of impaired calcium homeostasis in the skin. Biochim. Biophys. Acta. 1813, 11111117.

31. Tsukahara, H., Shibata, R., Ohshima, Y., Todoroki, Y., Sato, S., Ohta, N., Hiraoka, M. and Mayumi, M. 2003. Oxidative stress and altered antioxidant defenses in children with acute exacerbation of atopic dermatitis. Life Sci. 72, 2509-2516.

32. Ayala, A., Munoz, M.F. and Arguelles, S. 2014. Lipid peroxidation: production, metabolism, and signaling mechanisms of malondialdehyde and 4-hydroxy-2-nonenal. Oxid. Med. Cell Longev. 360-438.

33. Uttara, B., Singh, A.V., Zamboni, P. and Mahajan, R.T. 2009. Oxidative stress and neurodegenerative diseases: a review of upstream and downstream antioxidant therapeutic options. Curr. Neuropharmacol. 7, 65-74.

34. Kaur, G., Mishra, S., Sehgal, A. and Prasad, R. 2008. Alterations in lipid peroxidation and antioxidant status in pregnancy with preeclampsia. Mol. Cell Biochem. 313, 37-44.

35. Riahi, R.R., Bush, A.E. and Cohen, P.R. 2016. Topical retinoids: therapeutic mechanisms in the treatment of photodamaged skin. Am. J. Clin. Dermatol. 17, 265-276. 